\title{
Rejection by pigs of mouldy grain containing deoxynivalenol
}

\author{
C. J. MOORE*, B. J. BLANEY*, R. A. SPENCER† and R. L. DODMAN‡
}

Queensland Department of Primary Industries

\begin{abstract}
SUMMARY: Weaner pigs on a farm near Beaudesert in south eastern Queensland refused to eat feed comprised largely of wheat and barley. Older pigs consumed small amounts and some prepubertal gilts subsequently displayed enlarged and reddened vulvas. Wheat, barley and triticale were grown on the farm during 1983, which was unusually and persistently wet. The wheat and triticale were harvested and stored for about 3 weeks with moisture contents above $14 \%$ before being fed. Samples of the wheat and triticale contained pale pink grains, which can indicate infection by the fungus Fusarium graminearum Schw. On analysis 2 mycotoxins known to be produced by $F$. graminearum were detected, deoxynivalenol (vomitoxin) which causes feed refusal and vomiting, and zearalenone which causes oestrogenic effects. Concentrations of deoxynivalenol in the wheat, triticale and barley were 34,10 , and $<0.1 \mathrm{mg} / \mathrm{kg}$ respectively. Concentrations of zearalenone were $6.2,2.8$ and $0.1 \mathrm{mg} / \mathrm{kg}$ respectively. Subsequently, $F$. graminearum was isolated from grains and crop residues. Although the wet weather contributed to $F$. graminearum infection of the crops before harvest, most of the toxins probably developed during storage.

Aust. vet. J. 62: 60-62
\end{abstract}

\section{Introduction}

Grains fed to livestock in Australia occasionally suffer from weather damage and mould growth, which may be accompanied by mycotoxin contamination. Mycotoxins implicated in reduced production in countries with a temperate climate are the aflatoxins and ochratoxins produced by Aspergillus spp and Penicillium spp, as well as zearalenone and deoxynivalenol (vomitoxin), produced by Fusarium spp. Pigs appear to be more susceptible to the effects of these toxins than either poultry or cattle.

Reports from this Institute have described cases of intoxication of pigs by aflatoxin (Ketterer et al 1982) and zearalenone (Blaney et al 1984a). We now describe cases in which pigs refused to consume diets based on weatherdamaged grains in which we identified deoxynivalenol and zearalenone.

\section{Mycotoxin Assay \\ Analytical Methods}

Samples were hammer milled and then assayed for aflatoxins $B_{1}, B_{2}, G_{1}$ and $G_{2}$, ochratoxin $A$, sterigmatocystin, zearalenone and $\mathrm{T}-2$ toxin by a thin-layer-chromatographic screening method (Blaney et al 1984b).

Zearalenone was measured by the high performance liquid chromatographic method described by Blaney et al (1984b).

Deoxynivalenol, which is not easily detected in the screening assay, was extracted by the method of Scott et al (1981). The resultant extracts were then dissolved in $0.5 \mathrm{ml}$ of chloroform, and applied to short columns of silica-gel $\S$. The first $14 \mathrm{ml}$ of chloroform were discarded, and the deoxynivalenol was eluted with $10 \mathrm{ml}$ of methanol:chloroform (5:95). After evaporation of solvent, $100 \mu \mathrm{l}$ of $\mathrm{N}$-trimethylsilyl imidazole were added, and the mixture was allowed to stand for $1 \mathrm{~h}$ at room temperature $\left(25^{\circ} \mathrm{C}\right)$. Deoxynivalenol was identified using a Finnigan $1020 \mathrm{~B}$ gas chromatograph-mass spectrometer, fitted with a $30 \mathrm{~m}, \mathrm{SE}-54$, fused silica capillary column. Single ion monitoring at the molecular ion mass of 512 confirmed the presence of the trimethylsilyl derivative

- Animal Research Institute, Yeerongpilly, Queensland 4105 P.O. Box 96, Ipswich, Queensland 4305

$\ddagger$ P.O. Box 102, Toowoomba, Queensland 4350

$\S$ Sep-pak $®$ cartridges, Waters Associated Inc, Milford, MA01757, United States of America of deoxynivalenol. Measurement was performed on the reconstructed ion chromatogram by comparison of peak areas with that of standard deoxynivalenol.

\section{Fungal Isolation and Identification}

Fungal isolates were obtained from perithecia (the structure from which ascospores are released) on stubble, grain and glume (husk) samples. These produced perithecia of Gibberella zeae (Schw) Petch (the perithecial state of Fusarium graminearum Schw) when cultured on carnation leaf agar incubated under ultra violet light (Tio et al 1977).

\section{History}

Feed rejection by pigs was reported from 2 farms near Beaudesert in south east Queensland during January 1984. In one case the feed, described as wheat containing pink grains, was subsequently fed to dairy cows. However, efforts to obtain samples and more detailed information were unsuccessful. In the case investigated, various crops were grown on the farm (including maize in summer) to provide feed for a 45-sow piggery and a few chickens. Most of 1983 was unusually and persistently wet (Figure 1), and in late December crops of wheat, triticale and barley were harvested between periods of heavy rainfall. The grains were then stored in silos without drying. Three weeks later the wheat and barley were used to prepare diets for weaner, grower and breeder pigs. Concentrations of wheat in these diets were $60 \%, 40 \%$ and $35 \%$ respectively. Barley concentrations were $24 \%, 45 \%$ and $52 \%$ respectively.

When the diets were offered to the pigs the weaners completely rejected their feed. Feed intakes by grower pigs seemed to be reduced but sows were less affected. Molasses was added to the weaner diet but this was ineffective in promoting feed consumption. After 3 to 4 days some of the young gilts weighing 30 to $50 \mathrm{~kg}$ were observed with red and swollen vulvas. Consumption of the weaner diet was improved when it was diluted with an equal amount of proprietary feed. About 5 days after the diets were first offered, the weaners and growers had lost weight and the farm-mixed weaner and grower diets were withdrawn. The breeder diet was replaced several weeks later, when consumption had declined sufficiently to cause loss of weight during lactation.

Subsequently, new diets were prepared from the triticale (35 to $40 \%$ ) and barley $(45$ to $52 \%$ ), and these seemed to 


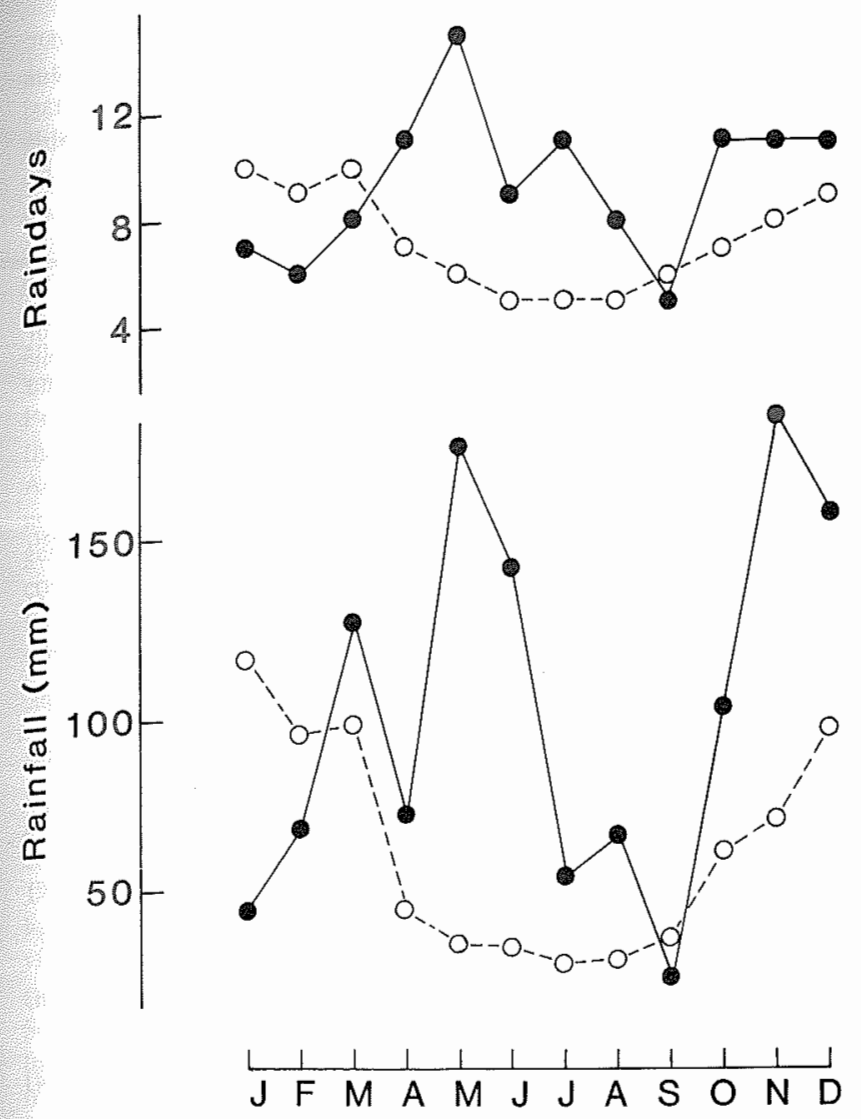

Figure 1. Monthly rainfall and rainy days at Beaudesert during 1983 , compared with the median rainfall and mean number of rain days during all previous years of record (approximately 90 observations). Solid line: Data for 1983. Broken Line: Data for all previous years of record.

be consumed readily by all pigs. About 4 weeks after the change to these new diets, the pigs appeared to be growing at a satisfactory rate although weight gains and feed consumptions were not recorded.

\section{Feed Assay}

Samples of wheat, triticale and barley which were examined had moisture contents of $14.5,14.2$ and $11.9 \%$, respectively. Both wheat and triticale were seen to contain grains with a pale pink discolouration. Since this discolouration may be caused by the fungus $F$. graminearum, we assayed the samples for mycotoxins, and detected deoxynivalenol and zearalenone which are produced by this fungus. Samples of the wheat and barley-based diets were also assayed (Table 1).

\section{Mycology}

Perithecia of $G$, zeaecontaining mature asci and ascospores were visible on stubble from the paddocks where the wheat and triticale were grown. These were more common on and

TABLE 1

Mycotoxin concentrations in grains and diets

\begin{tabular}{lcc} 
Sample & $\begin{array}{c}\text { Zearalenone } \\
(\mathrm{mg} / \mathrm{kg})\end{array}$ & $\begin{array}{c}\text { Deoxynivalenol } \\
(\mathrm{mg} / \mathrm{kg})\end{array}$ \\
\hline Wheat & 6.2 & 34.4 \\
Barley & 0.1 & 10.0 \\
Triticale & 2.8 & 17.3 \\
Weaner diet & 1.7 & 7.6 \\
Grower diet & 1.7 & 4.4 \\
Breeder diet & 1.6 & \\
\hline
\end{tabular}

* Not detected, $<0.1 \mathrm{mg} / \mathrm{kg}$
TABLE 2

Percentage (by weight) of grain samples with visible fungal mycelia and perithecia of Gibberella zeae

\begin{tabular}{|c|c|c|c|}
\hline Sample & $\begin{array}{l}\text { Grain with visible } \\
\text { pink-red mycelium } \\
\text { (without perithecia) }\end{array}$ & $\begin{array}{l}\text { Grain with } \\
\text { perithecia }\end{array}$ & $\begin{array}{l}\text { Unthrashed } \\
\text { grain (with } \\
\text { perithecia) }\end{array}$ \\
\hline Wheat & 21.6 & 4.4 & 21.6 \\
\hline Barley & 1.2 & 5.1 & 0 \\
\hline Triticale & 6.2 & 11.8 & 3.7 \\
\hline
\end{tabular}

around the nodes, particularly on the upper part of the stalk. Samples of the stored grains were first separated into thrashed grain, unthrashed grain and trash ( 1 to $7 \%$ of total). There were numerous perithecia on the glumes surrounding the unthrashed grain and on loose chaff in the grain. The thrashed grain was further separated into grain on which no mycelia and perithecia were visible, grain with visible pinkred mycelia but no perithecia, and grain with perithecia. The results are given in Table 2 .

\section{Toxicology Discussion}

Consumption of grain moulded with $F$. graminearum is known to produce 2 different syndromes. The first is an oestrogenic syndrome primarily due to zearalenone. The second involves refusal by pigs to consume the mouldy grain. Vomiting may occur if sufficient is consumed. Deoxynivalenol is a major contributing factor to this syndrome (Vesonder et al 1976). Poultry and cattle are much less susceptible than pigs to deoxynivalenol and zearalenone.

It was reported by Young et al (1983) that dietary deoxynivalenol concentrations of $20 \mathrm{mg} / \mathrm{kg}$ supplied to pigs in mouldy maize caused vomiting, $12 \mathrm{mg} / \mathrm{kg}$ caused almost complete feed refusal and $1.3 \mathrm{mg} / \mathrm{kg}$ significantly depressed feed intakes and rates of gain. Vomiting was not observed in the Beaudesert case, but the pigs were not closely observed when the diets were first offered. The concentrations of deoxynivalenol in the diets (Table 1) were sufficient to account for the observed feed refusal. Higher concentrations of toxins were present in the grain samples than are accounted for in the mixed diets, but the grain samples were "grab" samples, and not representative of the bulk in the silos. Although zearalenone was also present in the wheat, oestrogenic effects were small compared to those described by Blaney et al (1984a), since insufficient feed was consumed.

\section{Fungal Infection, Growth and Mycotoxin Production}

F. graminearum Grp 2 (Francis and Burgess 1977) causes cob and stalk rot of maize and head scab of wheat, barley and triticale. Head scab on the winter cereals is rare in Australia except in warm, humid regions where maize is grown during the summer and the fungus survives on crop debris such as maize stalks and cobs. Dispersal of fungal inoculum to growing crops may occur by rain splashing or wind-driven rain, but insects or birds may also act as vectors (Sutton 1982). The crops are most susceptible to fungal invasion during anthesis (flowering) and grain formation. Persistent wetness at this stage favours scab development. Epidemics of head scab of wheat in Canada have developed within single seasons (Sutton 1982). In head scab development, there is little opportunity for transfer of the fungus between plants. Disease severity is directly proportional to the amount of inoculum present and therefore to the amount of crop debris infected with F. graminearum.

Several factors probably contributed to head scab in the grains in the Beaudesert area. Firstly, there were maize crop residues on the soil. Secondly, the autumn and winter of 1983 were unusually and persistently wet (Figure 1), allowing build-up of inoculum on debris. Thirdly, anthesis and grain formation of the crops occurred in October which had a large number of rainy days. Coupled with heavy soils and uncontrolled weed growth, this provided continuous warm and humid conditions during this month. Perithecia of $F$. 
graminearum detected on the grains (Table 2) probably developed on the crop before harvest since perithecial development is stimulated by light.

Once the grain was infected, other factors contributed to mould growth and mycotoxin accumulation. The lighter diseased grain and glumes, which would normally be blown out of the harvester, remained with the wheat (Table 2) because thrashing plates were missing from the harvester and because the grain was harvested while wet, between rain storms. The wheat and triticale were then stored with moisture levels above $12 \%$, which are unsuitable for these grains. The relative proportions of wheat, triticale and barley with visible pink-red mycelia but no perithecia (Table 2), possibly reflects the degree of mould growth during storage of the grains, and roughly parallels the quantities of mycotoxins detected.

Factors contributing to toxin production by $F$. graminearum are complex. Relative concentrations of zearalenone, deoxynivalenol and possibly other toxins may be influenced by the particular isolate of $F$. graminearum, nature of the substrate, temperature, moisture concentration and gaseous environment (Greenhalgh et al 1983). In northern Queensland, F. graminearum infection of maize appears to be endemic (Blaney et al 1984b). However, although oestrogenic effects have been reported in pigs fed maize containing zearalenone (Blaney et al 1984a), there have been no reports of feed rejection by pigs in the region.

We consider that the conditions leading to these cases were unusual and unlikely to be repeated frequently in Australia. However, in the event of increased $F$. graminearum infection of crops due to unusual weather, mycotoxin concentrations may be minimised by ensuring that affected grains are dried before storage. Affected grain may be fed to chickens or cattle, which are less susceptible than pigs to deoxynivalenol and zearalenone. Low concentrations of affected grain may be used in the diets of pigs, although feed intakes could still be below optimum and the economics of this should be carefully assessed.

\section{Acknowledgments}

We thank K. C. Williams, G. M. Hawley, and A. L. Tyler for advice and technical assistance. A small quantity of pure deoxynivalenol was kindly provided by $R$. Greenhalgh of the Chemistry and Biology Research Institute, Agriculture Canada, Ottawa.

\section{References}

Blaney, B. J., Bloomfield, R. C. and Moore, C. J. (1984a) - Aust. vet. J. $61: 24$.

Blaney, B. J., Moore, C. 1. and Tyler, A. L. (1984b - Aust. J. agric. Res. 35: 473 .

Francis, R. G. and Burgess, L. W. (1977) - Trans. Br. mycol. Soc. 68: 421

Greenhalgh, R., Neish, G. A. and Miller, J. D. (1983) - Appl. environ. Microbiol. 46: 625

Ketterer, P. J., Blaney, B. J., Moore, C. J., Mclnnes, I. S. and Cook, P. W. (1982) - Aust. vet. J. 59: 113

Scott, P. M., Lau, P. -Y. and Kanhere, S. R. (1981) - J. Ass.off. anal. Chem, 64: 1364.

Sutton, J. C. (1982) - Can. J. Plant Path. 4: 195

Tio, M., Burgess, L. W., Nelson, P. E. and Toussoun, T. A. (1977) - Aust. Plant. Path. Soc. Newsi. 6: 11.

Vesonder, R. F., Ciegler, A., Jensen, A. H., Rohwedder, W. K. and Weisleder, D. (1976) - Appl. environ, Microbiol. 31: 280.

Young, L. G., McGirr, L., Valli, V. E., Lumsden, J. H. and Lun, A. (1983) - J. Anim. Sci. 57:655.

(Accepted for publication 27 July 1984)

\section{SHORT CONTRIBUTIONS}

\section{Geeldikkop in goats}

New South Wales Department of

Agriculture,

Regional Veterinary Laboratory,

Private Bag,

Wagga Wagga,

New South Wales 2650

113 Main Street,

West Wyalong,

G. K. BOAL

New South Wales 2671

Geeldikkop is a hepatogenous photosensitivity disease which causes severe economic loss among sheep and goats in the Republic of South Africa (Quin and Rimington 1935; Clare 1955; Brown 1966; van Tonder et al 1972; Kellerman et al 1980). Recently, 2 outbreaks of the disease involving sheep in New South Wales have been described (Glastonbury et al 1984). Field and experimental evidence indicates that geeldikkop is caused by an unidentified toxin in the annual herb Tribulus terrestris, acting in concert with sporidesmin produced by the saprophytic fungus, Pithomyces chartarum (Kellerman et al 1980). As geeldikkop has not been recorded previously in Australian goats, we would like to document its occurrence in a herd from the central western plains of New South Wales.

The disease occurred in a small Angora stud during early autumn 1983. Affected animals were detected in a group of 35 six-month-old, female kids which were grazing, in rotation, 2 paddocks, each of 1 ha. The paddocks were spray irrigated every 2 or 3 days. The pasture was dominated by a prolific growth of $T$. terrestris, but also contained subterranean clover (Trifolium subterrancum) burr, lucern (Mcdicago
Sativa) and mature rye grass (Lolium perenne) and barley grass (Hordeum leporinum). Six of the $35 \mathrm{kids}$ were clinically affected and of these, 2 succumbed, giving morbidity and case fatality rates of $17 \%$ and $33 \%$, respectively. Following diagnosis of photosensitisation the remainder of the mob was removed from the $T$. terrestris and no further cases occurred.

Seeking of shade and photophobia were the first clinical signs observed. Examination of the affected animals revealed subcutaneous oedema of the ears, eyelids, nose and submandibular region. Where the resultant swelling was most severe, a yellow serous fluid exuded from the surface of the skin. Affected goats rapidly lost weight and became dehydrated.

Treatment was initiated by moving the 6 affected kids to a darkened shed. Each animal was then given $2 \mathrm{ml}$ of dexamthasone* intravenously and $1 \mathrm{ml}$ of each of tripelennamine hydrochloride $f, B$ complex vitamins $\$$ and flunixin meglumine $\S$ intramuscularly. The treatments with tripelennamine hydrochloride and $\mathrm{B}$ complex vitamins were continued daily for 3 to 5 days. Two kids died following the course of treatment. The remaining 4 were confined indoors for 10 days and were force-fed leaves of loquat (Eriobotrya japonica) to stimulate appetite and rumination. At the end of this period the subcutaneous oedema had completely subsided and the kids appeared bright and alert. Ten months after the initial occurrence of the disease these animals remained clinically normal, although one was much smaller than its unaffected twin.

RWR Veterinary Products, Richmond, New South Wales Vetibenzamine(B), Ciba-Geigy Australia Ltd. Lane Cove, New South Wales

‡ Multibex $(B)$, VR/Syntex, Thornleigh, New South Wales $\$ \begin{aligned} & \text { Finadyne Solution }(B) \text {, Heriot Agencies Pty Ltd, Boronia, } \\ & \text { Victoria }\end{aligned}$ 